\title{
Important Parameters Optimization for Opening Cotton Device
}

\author{
Gaili Gao ${ }^{1}$, Hefei Zhao ${ }^{1}$, Jun Liu ${ }^{1}$, and Daoliang $\mathrm{Li}^{2, *}$ \\ ${ }^{1}$ College of Engineering, China Agricultural University, Beijing 100083, China \\ gg11965@126. com \\ ${ }^{2}$ College of Information and Electrical Engineering, China Agricultural University, \\ Beijing 100083, China \\ dlianglecau. edu.cn
}

\begin{abstract}
A new opening cotton device used in detecting and eliminating foreign fibers of cotton was presented in this paper. It is the first time to propose that the multi-variable nonlinear constrained optimization algorithm should be applied to obtain parameter values of the tooth profile of the opening roller and feed rollers as well as their diameter and rotating speed values. This approach was used to simultaneously consider the impact of all the performance parameters, and the important performance parameters may be weighted. As a matter of experience, the cotton fiber and foreign fibers were damaged small by the tooth profile of the opening roller and feed rollers. The foreign fibers could be easily detected and removed for they would not be torn.
\end{abstract}

Keywords: cotton, foreign fiber, opening roller, feed roller.

\section{Introduction}

Foreign fibers of cotton mainly include cloth strips, hemp ropes, the polypropylene fibers, plastic films, color yarns, feathers, hairs, and so on. In spinning process, the foreign fibers are not only eliminated difficultly, but also pulled, torn into shreds easily, and become tinier foreign fiber. They may have a strong impact on the strength of the yarn, and are not easy to be dyed [1-2]. In recent years, the domestic and foreign researchers have applied different techniques to identify various foreign fibers of raw cotton based on their characteristics of geometry, physics and spectroscopy. These techniques are machine vision at visible light and ultraviolet light wave, infrared spectroscopy, X-ray image, and so on [2-6]. Different kinds of sorter have been developed. However, some foreign fibers can only be detected and eliminated by the sorters. Two main factors may lead the foreign fibers in cotton not to be detected or eliminated. The first factor is that the polypropylene fiber which has the same color with cotton is hard to detect, and still exists in the yarn. The second factor is that the foreign fibers are increased dramatically after the cotton is opened, and it is hard to detect and eliminate the foreign fibers.

${ }^{*}$ Corresponding author. 
At present, many researchers focus on the opening roller in rotor spinning. Duru and Babaarslan (2003) suggested the opening roller speed should be high [7]. Mwasiagi et al. (2005) also proposed that the opening roller speed be $6500 \mathrm{rpm}$ [8]. However, Murugan et al. (2007) and Ulku et al. (1995) tested that fiber rupture had direct relationship with the opening roller speed and a high level of fiber damage caused by the opening roller occurred at high speed [9-10]. So the opening roller immediately influences the performance of the opened textile fiber, and then influences textile quality. The opening roller referred on rotor spinning is not suitable for the device of detecting and eliminating the cotton foreign fibers. Because the opening roller combs the cotton fiber too tiny, and cotton fiber is extremely injured. For this reason, a new opening cotton device used in detecting and eliminating the foreign fibers was proposed in this paper.

\section{Model of Opening Cotton Device}

A model of an opening cotton device for detecting and eliminating foreign fibers is shown in Fig. 1. The device mainly comprises a pressing roller, a conveying belt, two feed rollers, an opening roller and a cover plate. The pressing roller is set above the conveying belt. The two feed rollers are installed at one end of the conveyer belt. One of the two feed rollers is on the top of another. The opening roller is set under the cover plate, and near the two feed rollers.

When the opening cotton device is working cotton that is put on the conveying belt and compressed by the pressing roller is carried to the two feed rollers. The two feed rollers that rotate in opposite direction pick up the cotton and transfer it to the opening roller that rotates counterclockwise. The point and side of its saw teeth insert the cotton from the bottom to the middle and top gradually and cut up the cotton. When the cotton goes through separation zone between the opening roller and the cover plate cotton fiber is separated from the cotton. At the moment, the foreign fibers in the cotton are exposed in the surface of the cotton and can be detected effectively.

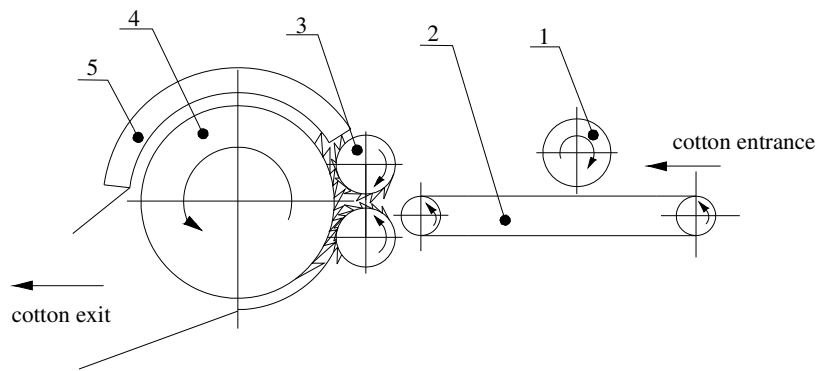

Fig. 1. Model of an opening cotton device.1-pressing roller; 2- conveying belt; 3- feed rollers; 4- opening roller; 5- cover plate. 


\section{Important Parameters Optimization for Opening Cotton Device}

\subsection{Building the Objective Function}

There are two requests to be contented for conveying cotton in the opening cotton device: (1) The two feed rollers may provide enough cotton for the opening roller. (2) In order to prevent the cotton plug, the feed rollers cannot feed too much cotton to the opening roller. For these reasons, the absolute value of $d$-value of the cotton volume that is carried by the feed rollers and picked up by the opening roller in the unit time is as optimizing objective function. The objective function may be expressed as follows:

$$
f=\left|C_{1} f_{1}-C_{2} f_{2}\right| \text {. }
$$

Where $f_{1}$ is the cotton volume that is picked up by the opening roller in the unit time $\left(\mathrm{mm}^{3} / \mathrm{s}\right), f_{2}$ is the cotton volume that is carried by the two feed rollers in the unit time $\left(\mathrm{mm}^{3} / \mathrm{s}\right), C_{1}$ and $C_{2}$ are weight coefficient. For the influence on transferring and opening cotton, important degree of $\mathrm{C} 1$ and $\mathrm{C} 2$ is the same, so $C_{1}=C_{2}=1$.

The cotton volume that is picked up by the opening roller in the unit time is the product of the total tooth number on the opening roller, rotational speed of the opening roller, the area of a single tooth profile and the width of base part of rack. The cotton volume may be described as follows:

$$
f_{1}=\frac{\pi}{25.4^{2}} d_{1} l z_{1} n_{1} S_{1} w_{1}
$$

Where $d_{1}$ is diameter of the opening roller $(\mathrm{mm}), l$ is length of the opening roller ( $\mathrm{mm}$ ), $z_{1}$ is tooth density of the opening roller, teeth $/(25.4 m m)^{2}, n_{1}$ is rotational speed of the opening roller $(r / s), S_{1}$ is area of a single tooth profile $\left(m m^{2}\right), w_{1}$ is width of base part of $\operatorname{rack}(\mathrm{mm})$.

The tooth profile of the opening roller is line rack with a minus angle $\delta$. Parameters of the tooth profile are shown in Fig.2.

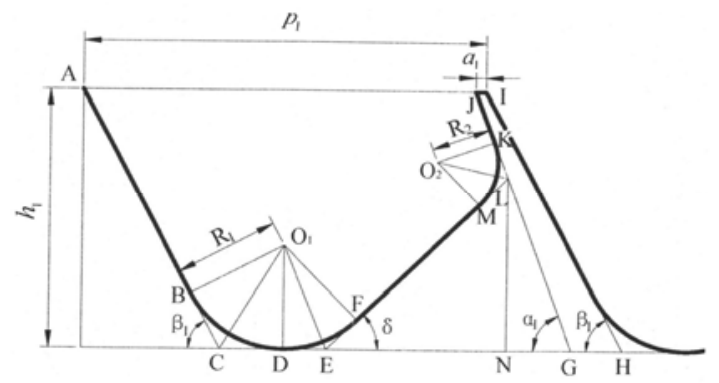

Fig. 2. Profile of the opening roller 
Area of the tooth profile may be expressed as follows:

$$
S_{1}=S_{A J G C}-S_{B C D}-S_{D E F}-S_{M L K}-S_{E L G} .
$$

Where

$$
\begin{gathered}
S_{A J G C}=h_{1}\left(p_{1}-a_{1}\right)-\frac{h_{1}^{2}}{2}\left(\cot \beta_{1}-\cot \alpha_{1}\right) \\
S_{B C D}=R_{1}^{2} \tan \frac{\beta_{1}}{2}-\frac{\beta_{1} R_{1}^{2}}{2} \\
S_{D E F}=R_{1}^{2} \tan \frac{\delta}{2}-\frac{\delta R_{1}^{2}}{2} \\
S_{M L K}=R_{2}^{2} \cot \frac{\delta+\alpha}{2}-\frac{\left(\pi-\delta-\alpha_{1}\right) R_{2}^{2}}{2} \\
S_{E L G}=\frac{\sin \alpha_{1} \sin \delta}{2 \sin \left(\delta+\alpha_{1}\right)}\left[p_{1}-a_{1}-h_{1}\left(\cot \beta_{1}-\cot \alpha_{1}\right)-R_{1}\left(\tan \frac{\beta_{1}}{2}+\tan \frac{\delta}{2}\right)\right]^{2}
\end{gathered}
$$

Where $h_{1}$ is tooth height of the opening roller $(m m), p_{1}$ is tooth pitch of the opening roller $(m m), a_{1}$ is the tooth top width of the opening roller $(m m), \alpha_{1}$ is working angle of the opening roller ( $\mathrm{rad}), \beta_{1}$ is tooth rack angle of the opening roller ( $\mathrm{rad}$ ), $\delta$ is minus angle ( $\mathrm{rad}$ ), $R_{1}$ is the radius of $\operatorname{arc} B F(\mathrm{~mm}), R_{2}$ is the radius of $\operatorname{arc} M K(\mathrm{~mm})$.

Substituting equations (4), (5), (6), (7) and (8) into equation (3) and rearranging terms gives:

$$
\begin{aligned}
S_{1}= & h_{1}\left(p_{1}-a_{1}\right)-\frac{h_{1}}{2}\left(\cot \beta_{1}-\cot \alpha_{1}\right)-R_{1}^{2}\left(\tan \frac{\beta_{1}}{2}+\tan \frac{\delta}{2}\right) \\
& +\frac{R_{1}^{2}}{2}\left(\beta_{1}+\delta\right)-R_{2}^{2} \cot \frac{\delta+\alpha_{1}}{2}+\frac{\left(\pi-\delta-\alpha_{1}\right) R_{2}^{2}}{2} \\
& -\frac{\sin \alpha_{1} \sin \delta}{2 \sin \left(\delta+\alpha_{1}\right)}\left[p_{1}-a_{1}-h_{1}\left(\cot \beta_{1}-\cot \alpha_{1}\right)-R_{1}\left(\tan \frac{\beta_{1}}{2}+\tan \frac{\delta}{2}\right)\right]^{2} .
\end{aligned}
$$

Substituting equation (9) into equation (2) yields: 


$$
\begin{aligned}
f_{1}= & \frac{\pi d_{1} l z_{1} n_{1} w_{1}}{25.4^{2}}\left\{h_{1}\left(p_{1}-a_{1}\right)-\frac{h_{1}}{2}\left(\cot \beta_{1}-\cot \alpha_{1}\right)-R_{1}^{2}\left(\tan \frac{\beta_{1}}{2}+\tan \frac{\delta}{2}\right)\right. \\
& +\frac{R_{1}^{2}}{2}\left(\beta_{1}+\delta\right)-R_{2}^{2} \cot \frac{\delta+\alpha_{1}}{2}+\frac{\left(\pi-\delta-\alpha_{1}\right) R_{2}^{2}}{2} \\
& \left.-\frac{\sin \alpha_{1} \sin \delta}{2 \sin \left(\delta+\alpha_{1}\right)}\left[p_{1}-a_{1}-h_{1}\left(\cot \beta_{1}-\cot \alpha_{1}\right)-R_{1}\left(\tan \frac{\beta_{1}}{2}+\tan \frac{\delta}{2}\right)\right]^{2}\right\} .
\end{aligned}
$$

The cotton volume that is carried by feed rollers in the unit time is the product of the total tooth number on the two feed rollers, rotational speed of the two feed rollers, the area of a single tooth profile and the width of base part of rack. The cotton volume may be described as follows:

$$
f_{2}=\frac{2 \pi}{25.4^{2}} d_{2} l z_{2} n_{2} S_{2} w_{2} .
$$

Where $d_{2}$ is diameter of the feed rollers $(\mathrm{mm}), l$ is length of the feed rollers $\left(\mathrm{mm}\right.$ ), namely the length of the opening roller, $z_{2}$ is tooth density of the feed rollers, teeth $/(25.4 m m)^{2}, n_{2}$ is rotational speed of the feed rollers $(r / s), S_{2}$ is area of a single tooth profile $\left(\mathrm{mm}^{2}\right), w_{2}$ is width of base part of rack $(\mathrm{mm})$.

The tooth profile of the feed rollers is line rack. Parameters of the tooth profile are shown in Fig.3.

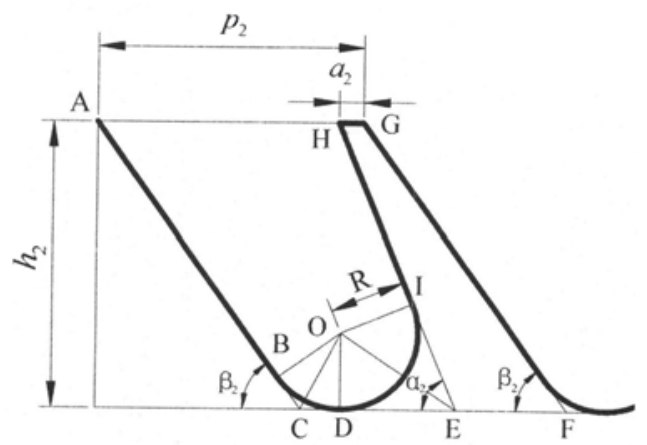

Fig. 3. Profile of the feed rollers

Area of the tooth profile may be expressed as follows:

$$
S_{2}=S_{A H E C}-S_{B C D}-S_{D E I}
$$

Where 


$$
\begin{gathered}
S_{A H E C}=\frac{h_{2}}{2}\left(R \tan \frac{\beta_{2}}{2}+R \cot \frac{\alpha_{2}}{2}+p_{2}-a_{2}\right) . \\
S_{B C D}=R^{2} \tan \frac{\beta_{2}}{2}-\frac{\beta_{2} R^{2}}{2} . \\
S_{D E I}=R^{2} \cot \frac{\alpha_{2}}{2}-\frac{\left(\pi-\alpha_{2}\right) R^{2}}{2} .
\end{gathered}
$$

Where $h_{2}$ is tooth height of the feed rollers $(\mathrm{mm}), p_{2}$ is tooth pitch of the feed rollers ( $m m), a_{2}$ is the tooth top width of the feed rollers ( $\mathrm{mm}$ ), $\alpha_{2}$ is working angle of the feed rollers ( $\mathrm{rad}), \beta_{2}$ is tooth rack angle of the feed rollers ( $\mathrm{rad}$ ), $R$ is the radius of arc $B D I(\mathrm{~mm})$.

Substituting equations (13), (14) and (15) into equation (12) and rearranging terms gives:

$$
S_{2}=R\left(\frac{h_{2}}{2}-R\right)\left(\tan \frac{\beta_{2}}{2}+\cot \frac{\alpha_{2}}{2}\right)+\frac{h_{2}}{2}\left(p_{2}-a_{2}\right)+\frac{\pi-\alpha_{2}+\beta_{2}}{2} R^{2} \text {. }
$$

Substituting equation (16) into equation (11) yields:

$$
\begin{aligned}
f_{2} & =\frac{2 \pi d_{2} l z_{2} n_{2} w_{2}}{25.4^{2}}\left[R\left(\frac{h_{2}}{2}-R\right)\left(\tan \frac{\beta_{2}}{2}+\cot \frac{\alpha_{2}}{2}\right)\right. \\
& \left.+\frac{h_{2}}{2}\left(p_{2}-a_{2}\right)+\frac{\pi-\alpha_{2}+\beta_{2}}{2} R^{2}\right] .
\end{aligned}
$$

Substituting equations (10) and (17) into equation (1), the objective function is:

$$
\begin{aligned}
f & =\mid \frac{\pi d_{1} l z_{1} n_{1} w_{1}}{25.4^{2}}\left\{h_{1}\left(p_{1}-a_{1}\right)-\frac{h_{1}}{2}\left(\cot \beta_{1}-\cot \alpha_{1}\right)-R_{1}^{2}\left(\tan \frac{\beta_{1}}{2}+\tan \frac{\delta}{2}\right)\right. \\
& +\frac{R_{1}^{2}}{2}\left(\beta_{1}+\delta\right)-R_{2}^{2} \cot \frac{\delta+\alpha_{1}}{2}+\frac{\left(\pi-\delta-\alpha_{1}\right) R_{2}^{2}}{2} \\
& \left.-\frac{\sin \alpha_{1} \sin \delta}{2 \sin \left(\delta+\alpha_{1}\right)}\left[p_{1}-a_{1}-h_{1}\left(\cot \beta_{1}-\cot \alpha_{1}\right)-R_{1}\left(\tan \frac{\beta_{1}}{2}+\tan \frac{\delta}{2}\right)\right]^{2}\right\} \\
- & \frac{2 \pi d_{2} l z_{2} n_{2} w_{2}}{25.4^{2}}\left[R\left(\frac{h_{2}}{2}-R\right)\left(\tan \frac{\beta_{2}}{2}+\cot \frac{\alpha_{2}}{2}\right)\right. \\
& \left.+\frac{h_{2}}{2}\left(p_{2}-a_{2}\right)+\frac{\pi-\alpha_{2}+\beta_{2}}{2} R^{2}\right] .
\end{aligned}
$$




\subsection{Choosing Optimized Parameters and Constraint Conditions}

The magnitude of the cotton volume that is picked up by the opening roller or carried by the feed rollers in the unit time is mainly determined by the tooth profile, tooth density, length, diameter and rotational speed. The shape of the tooth profile is relevant to the tooth pitch, the tooth height, the tooth top width, the working angle, the tooth rack angle, the minus angle and the arc radius. By experience, the working angle $\alpha_{1}$ and $\alpha_{2}$ are 75 degree. The magnitude of the length $l$ is proportional to the quantity of cotton that is carried by the device in the unit time, thus the magnitude of length $l$ should be determined by the quantity of opening cotton. According to analysis above, the optimized parameters are $d_{1}, d_{2}, n_{1}, n_{2}, z_{1}, z_{2}$, $p_{1}, p_{2}, h_{1}, h_{2}, \beta_{1}, \beta_{2}, \delta, a_{1}, a_{2}, R_{1}, R_{2}$ and $R$. The parameters are converted to the form that may be used in the optimizing function. The corresponding relationship is:

$$
\left(\begin{array}{l}
d_{1} \\
d_{2} \\
n_{1} \\
n_{2} \\
z_{1} \\
z_{2} \\
p_{1} \\
p_{2} \\
h_{1} \\
h_{2} \\
\beta_{1} \\
\beta_{2} \\
\delta \\
a_{1} \\
a_{2} \\
R_{1} \\
R_{2} \\
R
\end{array}\right) \Leftrightarrow\left(\begin{array}{l}
x_{1} \\
x_{2} \\
x_{3} \\
x_{4} \\
x_{5} \\
x_{6} \\
x_{7} \\
x_{8} \\
x_{9} \\
x_{10} \\
x_{11} \\
x_{12} \\
x_{13} \\
x_{14} \\
x_{15} \\
x_{16} \\
x_{17} \\
x_{18}
\end{array}\right)
$$

And the objective function may be written in the form

$$
f(x)=\left|f_{1}(x)-f_{2}(x)\right| .
$$

According to experimental data and experience formulas [11], the constraint conditions of the optimized parameters are given by: 
$320 \leq x_{1} \leq 360 \quad, \quad 55 \leq x_{2} \leq 65 \quad, \quad 15.8 \leq x_{3} \leq 27.5 \quad, \quad 0.67 \leq x_{4} \leq 1$, $30 \leq x_{5} \leq 40,30 \leq x_{6} \leq 50,5 \leq x_{7} \leq 6,5 \leq x_{8} \leq 6,3 \leq x_{9} \leq 5.6$, $3 \leq x_{10} \leq 4 \quad, \quad \frac{5 \pi}{18} \leq x_{11} \leq \frac{2 \pi}{5} \quad, \quad \frac{5 \pi}{18} \leq x_{12} \leq \frac{2 \pi}{5} \quad, \quad \frac{\pi}{6} \leq x_{13} \leq \frac{2 \pi}{9}$, $0.25 \leq x_{14} \leq 0.4,0.25 \leq x_{15} \leq 0.4,3 \leq x_{16} \leq 4,1 \leq x_{17} \leq 2,2 \leq x_{18} \leq 4$.

\subsection{Results and Discussions}

Objective function $f(x)$ is nonlinear. Constraint conditions are linear. It is the more parameters and nonlinear constraint optimization. In this paper, we adopt "fmincon" optimization function from MATLAB software $[12,13]$. The optimal values of the parameters of the opening roller and feed rollers are given in the following table.

Optimal values of parameters of the opening roller and feed rollers

\begin{tabular}{|c|c|}
\hline Names of parameters & $\begin{array}{c}\text { Optimal values } \\
\text { of parameters }\end{array}$ \\
\hline Diameter of the opening roller $d_{1}(\mathrm{~mm})$ & 320 \\
\hline Diameter of the feed rollers $d_{2}(\mathrm{~mm})$ & 65 \\
\hline Rotational speed of the opening roller $n_{1}(r / s)$ & 15.8 \\
\hline Rotational speed of the feed rollers $n_{2}(r / s)$ & 1.0 \\
\hline Tooth density of the opening roller $z_{1}$ (teeth $/(25.4 \mathrm{~mm})^{2}$ ) & 30 \\
\hline Tooth density of the feed rollers $z_{2}$ (teeth $/(25.4 \mathrm{~mm})^{2}$ ) & 50 \\
\hline Tooth pitch of the opening roller $p_{1}(\mathrm{~mm})$ & 5.0 \\
\hline Tooth pitch of the feed rollers $p_{2}(\mathrm{~mm})$ & 6.0 \\
\hline Tooth height of the opening roller $h_{1}(\mathrm{~mm})$ & 3.0 \\
\hline Tooth height of the feed rollers $h_{2}(\mathrm{~mm})$ & 4.0 \\
\hline Tooth rack angle of the opening roller $\beta_{1}$ (degree) & 72 \\
\hline Tooth rack angle of the feed rollers $\beta_{2}$ (degree) & 72 \\
\hline Minus angle $\delta$ (degree) & 30 \\
\hline The tooth top width of the opening roller $a_{1}(\mathrm{~mm})$ & 0.4 \\
\hline The tooth top width of the feed rollers $a_{2}(\mathrm{~mm})$ & 0.25 \\
\hline The radius of $\operatorname{arc} B F \quad R_{1}(\mathrm{~mm})$ & 3.0 \\
\hline The radius of $\operatorname{arc} M K \quad R_{2}(\mathrm{~mm})$ & 2.0 \\
\hline The radius of arc $B D I \quad R(\mathrm{~mm})$ & 4.0 \\
\hline
\end{tabular}




\section{Conclusions}

(1) In this paper, a new opening cotton device used in detecting and eliminating foreign fibers of cotton was presented. The cotton fiber and foreign fibers were damaged small by the new opening cotton device. The foreign fibers could be easily detected and removed for they would not be torn.

(2) The multi-variable nonlinear constrained optimization algorithm was selected to obtain parameter values of the tooth profile of the opening roller and feed rollers as well as their diameter and rotating speed values.

(3) It is the first time to propose that the multi-variable nonlinear constrained optimization algorithm should be applied to evaluate the design parameter values of the opening cotton device. This approach was used to simultaneously consider the impact of all performance parameters, and the important performance parameters may be weighted. This could get more reasonable parameter values.

\section{References}

1. Yang, W., Li, D., Zhu, L., Kang, Y., Li, F.: A new approach for image processing in foreign fiber detection. Comput. Electron. Agric. 68, 68-77 (2009)

2. Kang, Y., Li, W.: Development and application of lint foreign fiber cleaning equipment in cotton production line. China Cotton Processing (1), 12-14 (2010)

3. Li, B., Ding, T., Jia, D.: Design of a sophisticated foreign fiber separator. Nongye Jixie Xuebao 37, 107-110 (2006)

4. Guo, J., Ying, Y.: Progress on detecting technique and sorter of raw cotton foreign matters. Nongye Jixie Xuebao 39, 107-113, 106 (2008)

5. Zhang, X.B., Cao, B., Zhang, X.P., Shi, W.: Research on detecting heterogeneous fibre from cotton based on linear CCD camera. In: International Symposium on Photoelectronic Detection and Imaging 2009-Advances in Imaging Detectors and Applications, SPIE Digital Library, United States (2009)

6. Li, Y., Liang, K., Bai, H.Y.: Key technology in detecting and eliminating isomerism fibre in cotton. In: 2007 8th International Conference on Electronic Measurement and Instruments, ICEMI, pp. 4728-4732. Inst. of Elec. and Elec. Eng. Computer Society, United States (2007)

7. Duru, P.N., Babaarslan, O.: Determining an optimum opening roller speed for spinning polyester/waste blend rotor yarns. Text. Res. J. 73, 907-911 (2003)

8. Mwasiagi, J.I., Wang, X.H., Tuigong, D.R., Wang, J.: Study of rotor spun Basofil/cotton blended yarn quality characteristics during optimisation of processing parameters. J. Dong Hua Univ. 22, 1-5 (2005)

9. Murugan, R., Dasaradan, B.S., Karnan, P., Senthilkannan, M.S.: Fibre rupture phenomenon in rotor spinning. Fibers and Polymers 8, 665-668 (2007)

10. Ulku, S., Ozipek, B., Acar, M.: Effects of opening roller speed on the fiber and yarn properties in open-end friction spinning. Text. Res. J. 65, 557-563 (1995)

11. Fei, Q., Que, H., Chen, H., Wu, Q.: The technological characteristics, manufacture and use for carding. China Textile \& Apparel Press, Beijing (2007) (in Chinese)

12. Edward, B.M., Shapour, A., Balahumar, B., James, H.D., Keith, E.H., Gregory, C.W.: Principle and application of MATLAB, 2nd edn. Electronics industry press, Beijing (2006) (in Chinese)

13. Su, J., Ruan, S., Wang, Y.: MATLAB engineering mathematics. Electronics industry press, Beijing (2005) (in Chinese) 